Research Article

\title{
Sizing of the Propulsion System for a Heavy-Duty Fuel Cell Commercial Vehicle
}

\author{
Weiguang Zheng $\mathbb{D D}^{1,2}$ Weiwei Xin $\left.{ }^{1}\right)^{2,4}$ Enyong Xu ${ }^{1}{ }^{1,3}$ Shuilong He ${ }^{1}{ }^{4}{ }^{4}$ Jirong Qin, ${ }^{3}$ \\ and Heng Wang ${ }^{4}$ \\ ${ }^{1}$ State Key Laboratory of Digital Manufacturing Equipment and Technology, School of Mechanical Science and Engineering, \\ Huazhong University of Science and Technology, Wuhan 430074, China \\ ${ }^{2}$ School of Mechanical and Automotive Engineering, Guangxi University of Science and Technology, Liuzhou 545616, China \\ ${ }^{3}$ Commercial Vehicle Technology Center, Dong Feng Liuzhou Automobile Co., Ltd., Liuzhou 545005, China \\ ${ }^{4}$ School of Mechanical and Electrical Engineering, Guilin University of Electronic Technology, Guilin, 541004, China
}

Correspondence should be addressed to Enyong Xu; xuey@dflzm.com

Received 1 October 2021; Revised 23 November 2021; Accepted 6 December 2021; Published 21 December 2021

Academic Editor: Yi-Zhang Jiang

Copyright @ 2021 Weiguang Zheng et al. This is an open access article distributed under the Creative Commons Attribution License, which permits unrestricted use, distribution, and reproduction in any medium, provided the original work is properly cited.

\begin{abstract}
This paper presents a methodology for the sizing of a heavy-duty fuel cell commercial vehicle. The parameters scanning model and the long-term stochastic drive cycle are adopted for this proposed sizing framework. The dynamic programming algorithm is employed as the energy management strategy to assess the performance of sizing. The efficacy of this framework is evaluated, and a detailed analysis for the hydrogen consumption is given in the results. In addition, a prediction analysis based on the price performance of the next decade is also given in this work.
\end{abstract}

\section{Introduction}

The energy and environment are two limitations for the transportation industry $[1,2]$. The heavy-duty commercial vehicle is imperative to turn to new energy for its high fuel consumption and emission. As a fuel-renewable and environment-friendly on-board propulsion system, hydrogen fuel cells are of great significance for alleviating the current energy and environment dilemma.

Restricted by the dynamic properties of fuel cell, fuel cell vehicles (FCVs) are always equipped with at least two energy sources: a fuel cell stack and a battery pack or a supercapacitor, which are also known as fuel cell hybrid electric vehicles (FCHEVs) [3]. Therefore, FCHEV is generally treated as a particular electric vehicle which equipped with two or three power sources [4]. Many approaches are presented in the literature to optimize the vehicle operating cost, which can be divided into two levels: the optimization level and the design level. The optimal operation aims to find the optimal operating points for fuel cell to achieve the minimum hydrogen cost, which is determined by the energy management strategy (EMS). The optimal design aims to determine the optimal sizes of vehicle components $[5,6]$.

The key role of EMS for a FCHEV is to decide the power splitting for energy sources at each instant, while at the same time, the drivability constraints of vehicle must be satisfied [7]. There have been many researches on EMS to improve the fuel economy. In general, rule-based EMS and optimization-based EMS are two approaches widely studied $[8,9]$. Under current technology, rule-based EMS has been widely used in real vehicles' controller for its advantages in real time, simplicity, and cost. However, subjectivity and uncertainty of this strategy may lead the control rules far to the optimal rules [8]. On the other hand, thanks to the increasing computing power of on-board processors, more complex EMS has the potential to be applied in real vehicles; optimization-based EMS has become the focus of current academic research. Optimization-based EMS is often represented as optimization problems for constrained systems in finite-time domain; the common optimization algorithms 
include dynamic programming (DP) [10], Pontryagin's minimum principle (PMP) [11], and genetic algorithm (GA) [12]. In addition, two optimization frameworks (equivalent consumption minimization strategy (ECMS) [13] and model prediction control (MPC) [14-16]) are also applied to this strategy to improve the control effect.

In addition to the EMS, many researchers focused their attention on the sizing of energy sources to improve vehicle performance. The main purpose of sizing of energy sources is to optimize the dynamic and fuel economy with fewer cost; reasonable parameters can maximize the potential of a vehicle's EMS [17]. With the development of electric vehicle, numbers of algorithms have been adopted to solve this problem. As early as 2004, Lukic and Emadi [18] verified the influence of drivetrain hybridization on energy consumption and dynamic performance. In their work, the hybridization factor was defined, and the EMS was implemented as charge sustaining. Kim and Peng [19] proposed a combined optimization method of EMS and parameters sizing for FCHEV. Different subsystem-scaling models were adopted to predict the characteristics of components on different sizes, and a near-optimal EMS was designed with the inspiration of stochastic dynamic programming results. In [20], the scholars constructed a stochastic drive cycle to simulate the randomness of real-world driving conditions, and ECMS was used as an online EMS; the equivalent factors of ECMS were adjusted with the proposed sizing methodology. In [21], a parameters' sizing methodology based on ordinal optimization and dynamic programming was proposed. $\mathrm{Hu}$ et al. [22] gave a compared analysis for two optimization-based EMS, and the influence of downsizing the battery was also studied. In their further study, the influence of driving pattern on sizing was studied in [23]; the comparison of three different electrochemical energy storage systems and the sizing framework for hybrid electric vehicle are also given [24, 25]. In addition, Karaoğlan et al. [26] studied the influence of gear ratio on fuel economy and emissions.

For the EMS, optimization-based strategy has been the focus of current research; and for the parameters sizing, systematic algorithms are used to find the optimal/nearoptimal sizes of components for FCHEV; rule-based EMS or optimization-based EMS are adopted as an associated problem for these algorithms. Although existing research has proposed a number of approaches for parameters sizing, these approaches are based on the few drive cycles or only one standard drive cycle, and parameters' sizing for hybrid heavy-duty commercial vehicles is little studied.

In this paper, a sizing methodology for a fuel-cell/battery commercial vehicle is presented. It is based on the DP-based EMS and parameters scanning model, and a long-term stochastic drive cycle is adopted for the sizing framework. The main contributions are as follows: (a) A long-term stochastic drive cycle that is based on the cluster and stochastic procedure is adopted, and the processes of generate stochastic drive cycle are also available. (b) A detailed analysis on oversizing the fuel cell stack and battery is given. (c) A predictive analysis is also given with considering the price performance in the next decade.
The remainder of this paper is organized as follows. In Section 2, the model of a heavy-duty fuel cell commercial vehicle is established. In Section 3, the design process of the long-term stochastic drive cycle is proposed. In Section 4, the DP-based EMS is introduced. In Section 5, the sizing methodology of propulsion system is presented. Section 6, provides results and discussion, and in Section 7, the conclusion of this paper is given.

\section{Mathematical Model of an FCHEV}

In general, for an FCHEV, fuel cell stack is employed as the main power source, and battery is adopted as an energy storage system, which is also known as the auxiliary source. The structure of selected FCHEV is shown in Figure 1. The electric motor is the only conversion equipment of electric energy and kinetic energy, fuel cell stack and battery pack composed of the propulsion system to provide power to permanent magnet synchronous motor and the motor's inverter (DC-AC), and a DC-DC converter is used to boost the voltage from fuel cell stack to DC bus. In this work, the powertrain system is divided into a combined propulsion subsystem and a transmission subsystem. The parameters sizing of propulsion system is the main work of this paper.

2.1. Vehicle and Drivetrain. The mathematical model building of FCHEV is reversed with the target of tracking drive cycle, and the impacts of lateral dynamics and rotating mass are ignored. At every moment of vehicle's operation, the torque $T_{w}$ and speed $\omega_{w}$ of wheels are given by

$$
\begin{aligned}
T_{w} & =r\left(m \frac{\mathrm{d} v}{\mathrm{~d} t}+\frac{1}{2} \rho C_{d} A_{f} v^{2}+m g f \cos (\alpha)+m g \sin (\alpha)\right), \\
\omega_{w} & =\frac{v}{r}
\end{aligned}
$$

where $r$ is the rolling radius of the wheel, $m$ the FCHEV's mass with full load; $v$ the vehicle's velocity at the current moment; $\rho$ the air density; $A_{f}$ the frontal area; $C_{d}$ the aerodynamic drag's coefficient; $f$ the rolling resistance coefficient; $\alpha$ the road's inclination angle. The motor's torque $T_{m}$, speed $\omega_{m}$, and power $P_{m}$ are formulated as follows:

$$
\begin{gathered}
T_{m}= \begin{cases}\frac{T_{w}}{\eta_{f d} r_{f d}}, & T_{w} \geq 0, \\
\frac{T_{w} \eta_{f d}}{r_{f d}}, & T_{w}<0,\end{cases} \\
\omega_{m}=\omega_{w} r_{f d}, \\
P_{m}= \begin{cases}\frac{T_{m} \omega_{m}}{\eta_{m}}, & T_{m} \geq 0, \\
T_{m} \omega_{m} \eta_{m}, & T_{m}<0,\end{cases}
\end{gathered}
$$




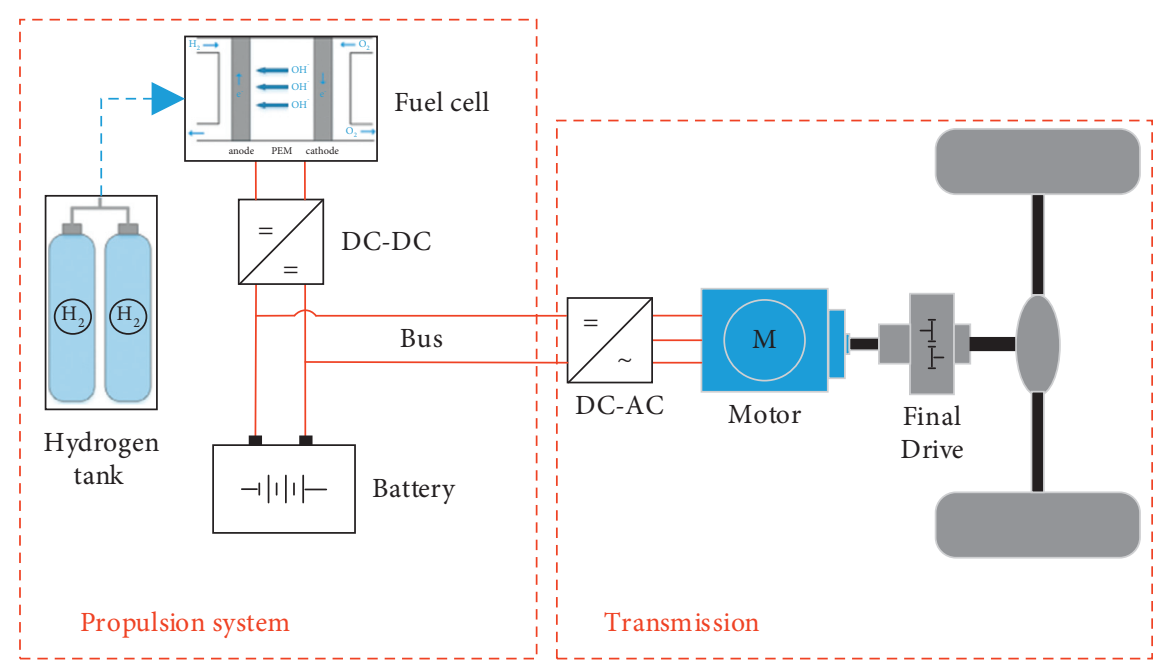

FIGURE 1: Block diagram of FCHEV. The blue dotted lines, red thin solid lines, and black thick solid lines represent the hydrogen gas flow channel, the electrical connections and mechanical connections of FCHEV, respectively.

where $\eta_{f d}$ and $r_{f d}$ are the efficiency and gear ratio of the final drive, respectively.

For this work, the motor power is defined as positive during traction while negative during breaking. The propulsion system consists of fuel cell stack and battery pack outputs the power demand of the motor, as shown in the following formula:

$$
P_{m}=P_{\text {stack }}+P_{\text {pack }}
$$

where $P_{\text {stack }}$ and $P_{\text {pack }}$ are the power of fuel cell stack and battery pack. Parameters of the heavy-duty fuel cell commercial vehicle are listed in Table 1.

2.2. Fuel Cell Stack. Fuel cell is an electrical device that converts chemical energy into electricity. Proton exchange membrane fuel cell (PEMFC) is the most common on-board propulsion system for fuel cell vehicles. A complete onboard PEMFC system includes fuel cell stack, hydrogen storage system, hydrogen circuit, air circuit, water circuit, and coolant circuit [3]. The models for these systems are very complicated. This work is mainly concerned with the powersplit of the bus but not the detailed conversion process of fuel cells. Therefore, a simple efficiency graph model is used for the simulation.

In this selected model, hydrogen consumption and efficiency of the fuel cell stack are both formulated as the function of power demand; these datasets are obtained through testing, which have been provided in ADVISOR (FC_ANL50H2) [27]. Scaling models are adopted to facilitate parameters' sizing, as shown in Figure 2.

2.3. Battery Pack. Benefiting from the high power density and high reliability, lithium-ion batteries have become the most commonly used energy storage system for FCHEV. The purpose of adding a battery pack into the propulsion system is to improve the drivability and efficiency performance of the vehicle.
TABLE 1: Parameters of the FCHEV.

\begin{tabular}{lc}
\hline Parameters & Value \\
\hline Vehicle total mass $(\mathrm{kg})$ & 9000 \\
Air density $\left(\mathrm{kg} / \mathrm{m}^{3}\right)$ & 1.2 \\
Aerodynamic drag coefficient & 0.563 \\
Vehicle frontal area $\left(\mathrm{m}^{2}\right)$ & 6.6454 \\
Wheel radius $(\mathrm{m})$ & 0.413 \\
Gear ratio & 6.67 \\
Efficiency of transmission $(\%)$ & 98 \\
Rolling resistance coefficient & 0.015 \\
Efficiency of converter (\%) & 98 \\
Efficiency of inverter (\%) & 98 \\
Efficiency of charge $(\%)$ & 90 \\
Efficiency of discharge (\%) & 100 \\
\hline
\end{tabular}

For the model of battery pack, the circuit model is used for simulation. In this model, the battery is equivalent to a circuit with an ideal voltage source and an internal resistance. When the battery pack is operating, its current and power are formulated as follows:

$$
I_{\text {bat }}=\frac{V_{o c}-\sqrt{V_{o c}^{2}-4 R_{\mathrm{int}} P_{\mathrm{pack}}}}{2 R_{\mathrm{int}}},
$$

where $V_{o c}$ is the open circuit voltage, $I_{\text {bat }}$ the current, $R_{\text {int }}$ the internal resistance, and $P_{\text {pack }}$ the power of battery pack. These parameters can be obtained from equations (5) to (7).

$$
\begin{gathered}
P_{\text {pack }}=P_{\text {bat }} n_{\text {bat }}, \\
V_{o c}=\frac{V_{o c} n_{s}}{n_{p}}, \\
R_{\text {int }}=\frac{r_{\text {int }} n_{s}}{n_{p}},
\end{gathered}
$$

where $\eta_{\text {bat }}$ is the conversion efficiency for charge/discharge, $n_{s}$ the series number of cells, and $n_{p}$ the parallel number of 


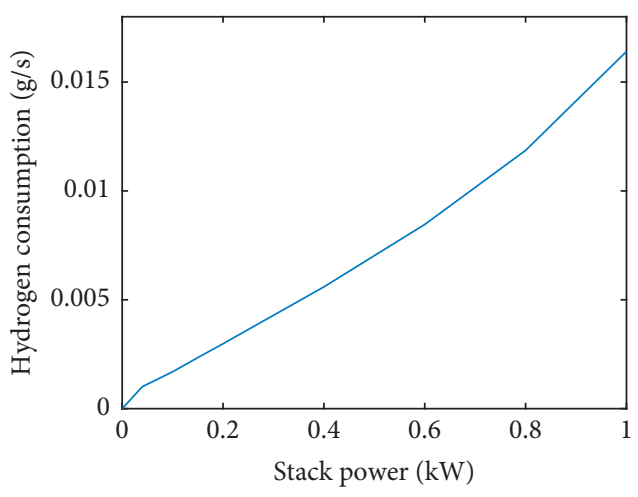

(a)

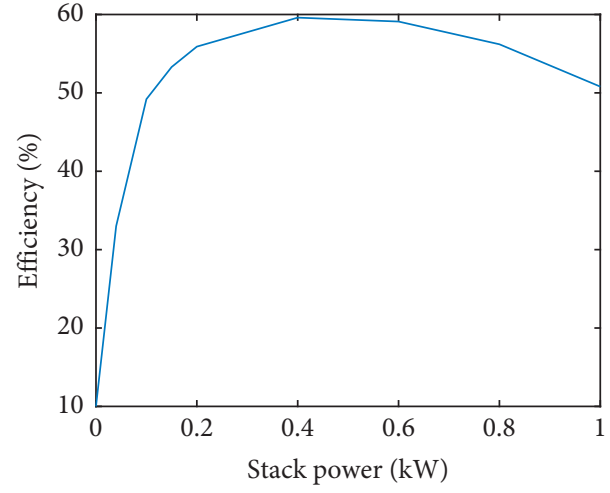

(b)

FIgURE 2: Scaling models of fuel cell stack (on the basis of a fuel cell stack with $50 \mathrm{~kW}$ peak power on ADVISOR). (a) Hydrogen consumption at different stack power. (b) Efficiency at different stack power.

cells. The state of charge (SOC) of battery at time step $k$ is defined as

$$
\operatorname{soc}(k)=\operatorname{soc}(k-1)-\frac{I_{\mathrm{bat}}}{Q_{\mathrm{bat}}},
$$

where $Q_{\text {bat }}$ is the capacity of battery pack.

$R_{\text {int }}$ and $P_{\text {pack }}$ are the functions of SOC, as shown in Figure 3.

It is worth mentioning that the battery pack is composed of strings connected in parallel, with each string containing the same number of cells in series. More detailed descriptions about configuration and modelling of battery pack are available in [23].

2.4. Drive Motor. For an FCHEV, the drive motor's function mainly includes the following two parts: (a) converting the electrical energy from bus to mechanical energy to drive the vehicle and (b) recycling the vehicle's braking power to charge the battery. A permanent magnet synchronous motor (PMSM) is adopted for its compact and high efficiency. The model of drive motor is based on its efficiency map, as shown in Figure 4.

\section{Long-Term Stochastic Drive Cycle}

The drive cycle refers to the driving characteristics of a certain type of vehicle (passenger car, bus, and cargo vehicle, etc.) in a specific condition (urban, suburban, highway, etc.); it is generally a set of points representing speed versus time. There have been many systems of typical driving cycles around the world.

Although the representativeness of cycles will be considered in the design process of typical drive cycle, the optimization results obtained under few drive cycles cannot satisfy the randomness of real driving conditions [20]. Therefore, a long-term stochastic drive cycle is built to overcome this drawback. The constructed drive cycle is based on the typical drive cycles of heavy commercial vehicles, and cluster analysis and random process are adopted. The flowchart of this procedure is shown in Figure 5.
In this work, eight typical drive cycles for commercial vehicles are introduced as the DC library, which are numbered and shown in Figure 6. Twelve characteristic parameters are used for clustering, and the corresponding descriptions of these parameters are listed in Table 2. The characteristic parameters for each drive cycle are calculated and listed in Table 3. These parameters will be the raw data of clustering.

Hierarchical clustering and Euclidean distance are adopted to obtain the similar degree of the different drive cycles. The clustering results are shown in Figure 7. The library is divided into 5 classes with the benchmark of similarity to 1 : the first category includes drive cycles $1,4,6$, and 8 , and drive cycles $2,7,3$, and 5 are classified as the second to fifth categories, respectively. The drive cycles 8 (CHTC_HT), 2 (WVUCITY), 7 (NYCOMP), 3 (WVUINTER), and 5 (UDDSSHCV) are selected as the representatives of each category. These five drive cycles will be regarded as the originals in the long-term stochastic drive cycle.

The next step for this work is to build the combined drive cycle, which is generated from the original drive cycles. After that, the combined drive cycle will be divided into microtrips and microidles. A microtrip is a segment of the drive cycle where the velocity is not equal to zero, and a microidle is the segment where the velocity is equal to zero. The relationship between microtrips and microidles is depicted in Figure 8 . Then, the divided segments are added to the stochastic drive cycle randomly. In this process, the microtrips and microidles are scaled with a stochastic procedure. The scaling processes for microtrips are for their velocity, and for microidles, it is for their length of time, the scaling factors are both defined as a stochastic number from 0.8 to 1.2. To follow the objective laws for drive cycles, the microtrip and microidle should be added in turn, which means after adding a microtrip, a microidle must be added as its follow-up. In addition, the long-term stochastic drive cycle can more effectively reflect the randomness of the drive cycle, the total length of stochastic drive cycle is set as 10 times that in the combined drive cycle in this work. 


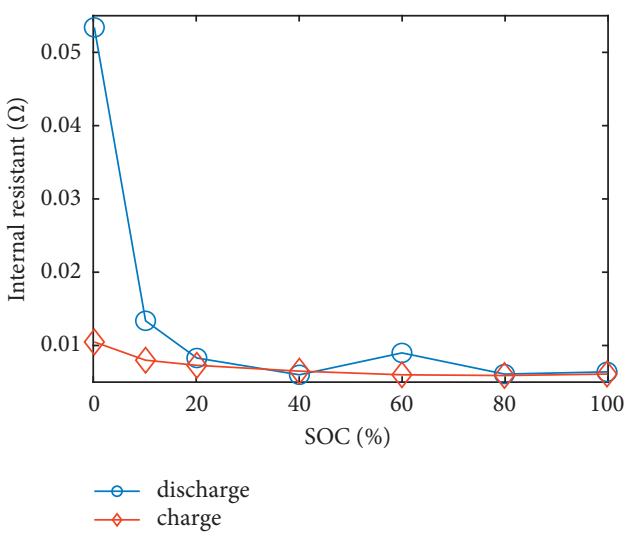

(a)

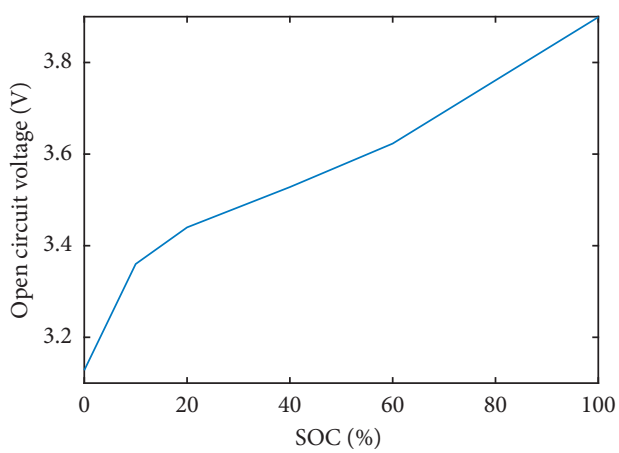

(b)

FIGURE 3: Circuit voltage and internal resistance of the cell. (a) Resistances of cell for different SOC in charge and discharge state. (b) Open circuit voltage of cell for different SOC.

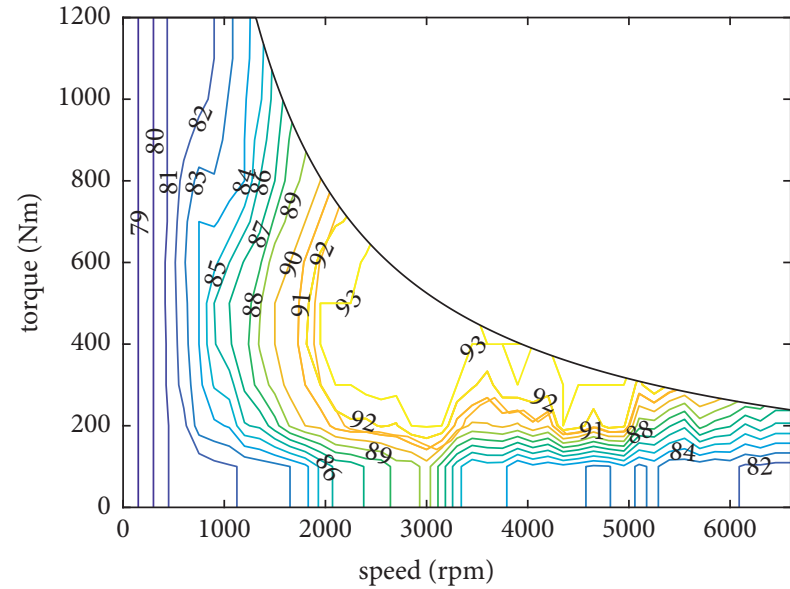

Figure 4: Efficiency map of PMSM.

Another noteworthy point for this process is that after the scaling of a microtrip, three indexes should be detected: the maximum speed, maximum acceleration, and maximum deceleration. If any index is higher than the combined drive cycle, the scaling process should be repeated until satisfied.

After completing the construction of long-term stochastic drive cycle, evaluation indexes are introduced to evaluate the rationality. Figure 9 illustrates the distribution of two drive cycles; Table 4 depicts the comparison of characteristics of combined drive cycle and long-term stochastic drive cycle. The above charts show that the long-term stochastic drive can accurately reflect the characteristics of original cycles.

\section{DP-Based EMS}

In general, the EMS for FCHEV has a great impact on efficiency. In this work, an optimal EMS based on dynamic programming algorithm is adopted to assess the economic potential of sizing.

Dynamic programming is a numerical method for solving multistage decision-making problems. It can provide

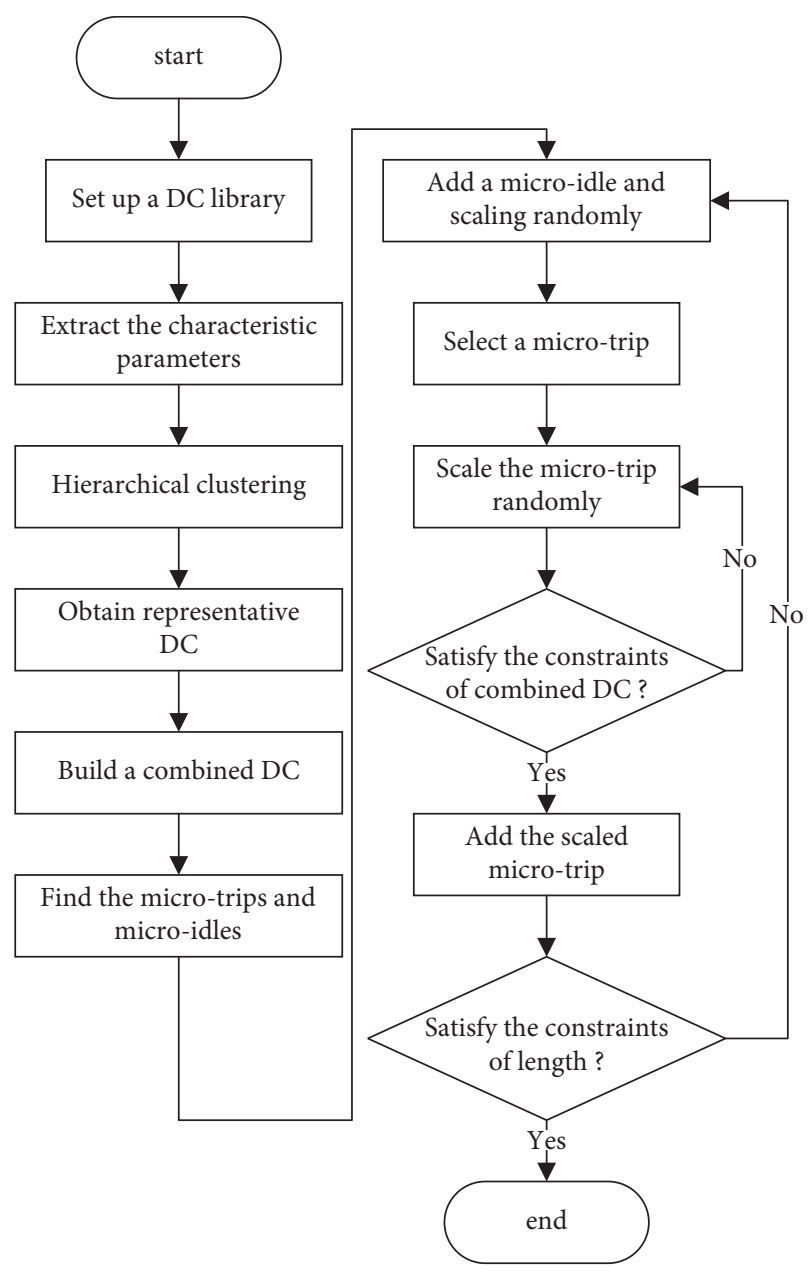

FIGURE 5: Flowchart of long-term stochastic drive cycle generation. DC: drive cycle.

the optimal solution for problems of any complexity level in the limits of computational capabilities [7].

For a controlled multistage decision-making problem, the state transfer function can be described as 


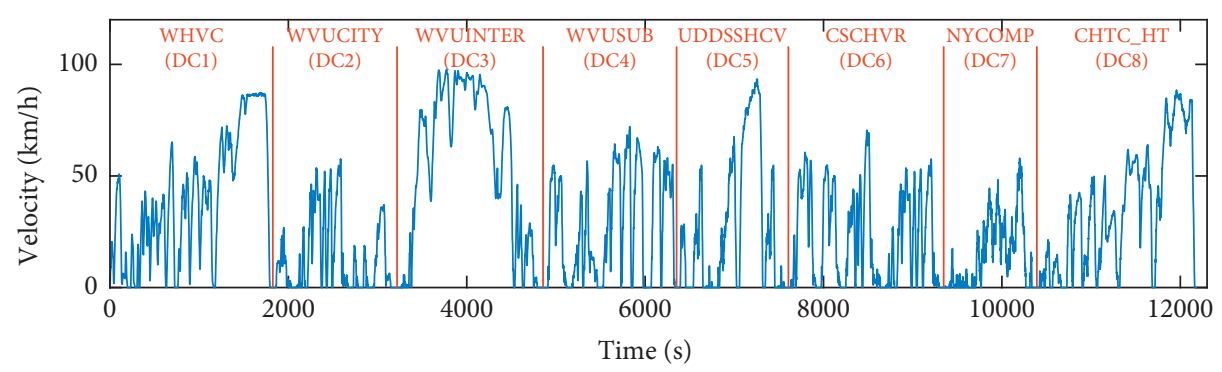

FIgURE 6: The serial number of the selected drive cycles.

TABLE 2: The characteristic parameters used for clustering.

Parameter Denotation

Average velocity $(\mathrm{m} / \mathrm{s})$

Average acceleration $\left(\mathrm{m} / \mathrm{s}^{2}\right)$

Average deceleration $\left(\mathrm{m} / \mathrm{s}^{2}\right)$

Standard deviation of velocity

Maximum velocity $(\mathrm{m} / \mathrm{s})$

Maximum acceleration $\left(\mathrm{m} / \mathrm{s}^{2}\right)$

Maximum deceleration $\left(\mathrm{m} / \mathrm{s}^{2}\right)$

The percentage of time in speed interval $0-20 \mathrm{~km} / \mathrm{h}(\%)$

The percentage of time in speed interval $20-40 \mathrm{~km} / \mathrm{h}(\%)$

The percentage of time in speed interval $40-60 \mathrm{~km} / \mathrm{h}(\%)$

The percentage of time in speed $>60 \mathrm{~km} / \mathrm{h}(\%)$

The percentage of time in idle state $(\%)$

TABle 3: The characteristic parameters that are calculated for each drive cycle.

\begin{tabular}{|c|c|c|c|c|c|c|c|c|}
\hline Denotation & DC1 & DC2 & DC3 & DC4 & DC5 & DC6 & DC7 & DC8 \\
\hline $\bar{v}$ & 11.25 & 3.78 & 15.22 & 7.19 & 8.42 & 6.07 & 3.92 & 9.62 \\
\hline $\bar{a}$ & 0.23 & 0.30 & 0.20 & 0.33 & 0.48 & 0.39 & 0.47 & 0.22 \\
\hline $\bar{d}$ & 0.28 & 0.39 & 0.21 & 0.42 & 0.58 & 0.46 & 0.54 & 0.29 \\
\hline$\sigma_{v}$ & 7.81 & 4.58 & 9.77 & 6.56 & 8.87 & 5.82 & 4.23 & 7.61 \\
\hline$v_{\max }$ & 24.25 & 16.01 & 27.15 & 20.03 & 25.93 & 19.58 & 16.09 & 24.58 \\
\hline$a_{\max }$ & 0.82 & 1.14 & 1.42 & 1.29 & 1.96 & 1.16 & 2.06 & 1.22 \\
\hline$d_{\max }$ & 1.17 & 2.24 & 1.86 & 2.16 & 2.07 & 1.79 & 1.95 & 1.25 \\
\hline$\theta_{0-20}$ & 21.93 & 41.26 & 15.85 & 24.86 & 16.49 & 31.56 & 33.98 & 22.56 \\
\hline$\theta_{20-40}$ & 23.10 & 17.19 & 9.21 & 13.51 & 15.83 & 19.43 & 25.63 & 22.67 \\
\hline$\theta_{40-60}$ & 21.65 & 11.29 & 11.83 & 28.53 & 12.06 & 24.76 & 7.28 & 20.61 \\
\hline$\theta_{60-\max }$ & 26.49 & 0 & 53.84 & 7.93 & 22.34 & 2.64 & 0 & 19.89 \\
\hline$\theta_{0}$ & 6.38 & 30.26 & 9.27 & 25.17 & 33.27 & 21.62 & 33.11 & 14.28 \\
\hline
\end{tabular}

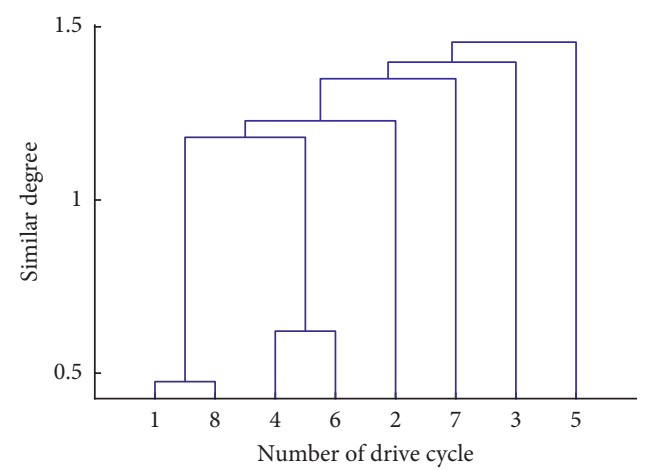

FIGURE 7: Results of hierarchical clustering. 


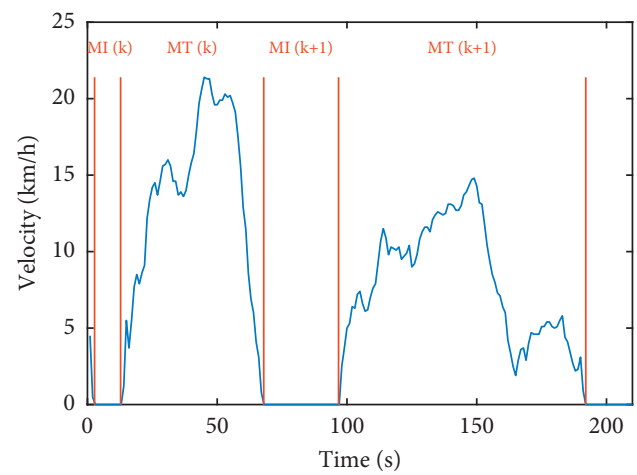

FIGURE 8: Relationship of the microtrips and microidles. The MI(k) and MT(k) represent the kth microidle and microtrip, respectively.

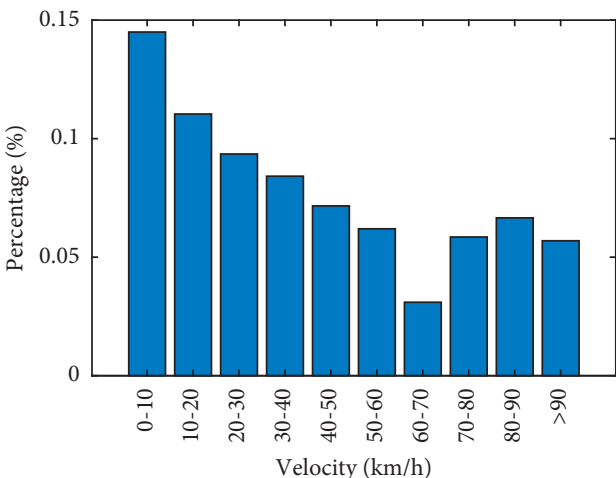

(a)

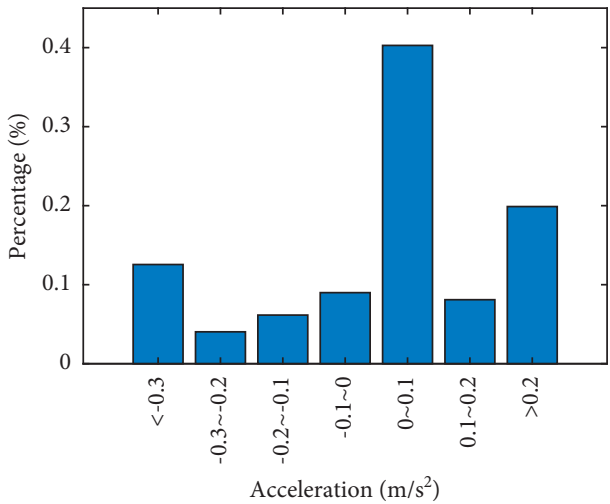

(c)

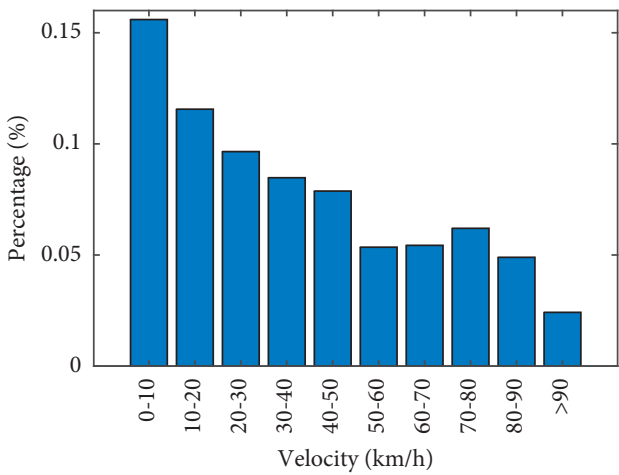

(b)

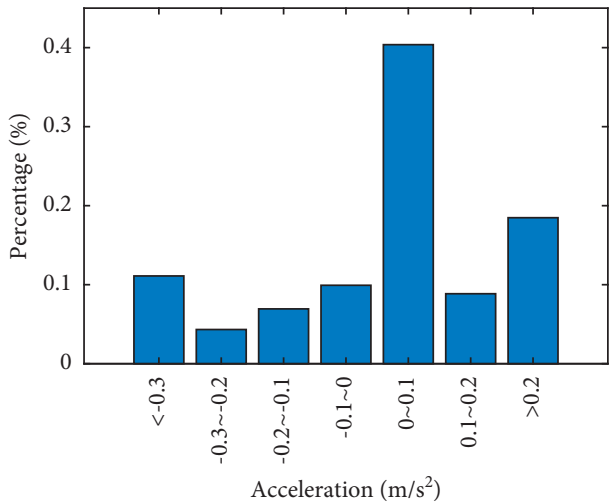

(d)

Figure 9: The distribution of velocity and acceleration for two drive cycles. (a) The percentage of speed for combined drive cycle. (b) The percentage of speed for long-term stochastic drive cycle. (c) The percentage of acceleration for combined drive cycle. (d) The percentage of acceleration for long-term stochastic drive cycle.

TABLe 4: The characteristics of two drive cycles.

\begin{tabular}{lcc}
\hline Characteristics & Combined DC & Stochastic DC \\
\hline Duration (s) & 6939 & 69393 \\
Idle time (\%) & 22.03 & 24.38 \\
Maximum velocity (m/s) & 27.15 & 27.08 \\
Average velocity (m/s) & 8.73 & 6.85 \\
Standard deviation of velocity & 8.66 & 7.06 \\
Maximum acceleration $\left(\mathrm{m} / \mathrm{s}^{2}\right)$ & 2.07 & 2.06 \\
Maximum deceleration $\left(\mathrm{m} / \mathrm{s}^{2}\right)$ & 3.24 & 3.17 \\
Average acceleration $\left(\mathrm{m} / \mathrm{s}^{2}\right)$ & 0.29 & 0.28 \\
Average deceleration $\left(\mathrm{m} / \mathrm{s}^{2}\right)$ & 0.35 & 0.34 \\
\hline
\end{tabular}




$$
s(k+1)=f_{k}(s(k), u(k)),
$$

where $s(k)$ is the state variable at time $k$ and $u(k)$ is the control variable. For a control policy $u=\left\{u_{0}, u_{1}, \ldots u_{N-1}\right\}$, the cost in time step $N$ is defined as

$$
J\left(s_{0}, u\right)=L_{N}\left(s_{N}\right)+\sum_{k=1}^{N-1} L_{k}\left(s_{k}, u_{k}\right),
$$

where $L_{k}$ is the instantaneous cost function. The optimal cost is

$$
J^{*}\left(s_{0}\right)=\min \left(J\left(s_{0}, u\right), u\right) .
$$

The optimal control policy $u^{*}=\left\{u_{1}^{*}, u_{2}^{*}, \ldots, u_{N-1}^{*}\right\}$.

For the DP-based EMS for FCHEV, the SOC of battery is selected as the state variable, and the output power of fuel cell stack is adopted as the control variable. The state transfer function is defined as follows:

$$
\operatorname{SOC}(k+1)=\operatorname{SOC}(k)+h_{k}\left(P_{\text {stack }}\right),
$$

where $h_{k}\left(P_{\text {stack }}\right)$ is the change rate of state in time $k$, which can be obtained with equations (7) to (11).

For the structure of non-plug-in FCHEV, a constraint of terminal SOC is required to sustain the energy storage system. In principle, the constraint of terminal SOC can be taken into account in two different ways, namely, as a soft constraint or a hard constraint. In this study, a hard constraint is adopted by requiring that the energy storage stored at the end of the mission equal to the value at the start of the mission, as shown in equation (13). A more detailed explanation will be found in [28-30]. Other parameters under constraints are listed in equation (14). In particular, the $\mathrm{SOC}_{\min }$ and $\mathrm{SOC}_{\max }$ are set to 0.4 and 0.8 , respectively.

$$
\begin{aligned}
& \operatorname{SOC}(\text { end })=\operatorname{SOC}(0) \text {, }
\end{aligned}
$$

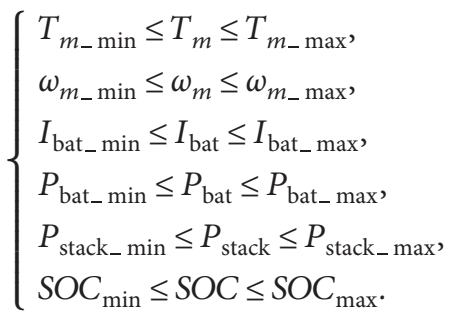

\section{Structure of Parameters' Sizing}

The objective of sizing is to obtain the near-optimal sizes of maximum power of fuel cell stack $\left(P_{\text {stack_max }}\right)$ and the number of battery cell $\left(n_{\text {bat }}\right)$. The sizes of propulsion should satisfy the following objectives: (a) meet the drivability and (b) minimize the operating cost of the vehicle during its life cycle.

For drivability, passenger cars typically have higher velocity and acceleration targets, while for commercial vehicles, equipped with large load mass, the vehicle's climbing performance always receives more attention. Therefore, the sizing method is tested with three subobjects: (a) The peak power of fuel cell stack alone must be able to sustain the maximum velocity; (b) the peak power with fuel cell stack and battery pack together must meets the maximum climbing slope index at a given velocity; (c) the power with fuel cell stack and battery pack together should fulfil the power demand of long-term stochastic drive cycle. The first subobject is used to obtain the low limiting value of $P_{\text {stack_max }}$, and the others are used to determine $n_{\text {bat }}$. It should be noted that the for the subobject (c), the verification results are related to the selected EMS, DP-based strategy is employed for this work, which has been introduced in Section 4.

This sizing methodology is based on the generated longterm stochastic drive cycle, a parameters' scanning model is added for sizing, and the dynamic programming algorithm is adopted for the EMS. The flowchart of this proposed methodology is shown in Figure 10.

In this sizing methodology, the range of fuel cell stack's peak power is divided into $i_{\max }$ independent nodes; the range of battery cell's number is divided into $j_{\max }$ independent notes; thses two groups of nodes constitute a crossover model with $\left(i_{\max } \times j_{\max }\right)$ crossover points, and for each crossover point, there is an FCHEV model corresponding to it. The optimal cost for each size is obtained by DP-based EMS. In addition, the low limiting value of $P_{\text {stack_max }}$ should meet the power demand of the vehicle at a maximum velocity (equation (15)), and the peak-powers provided by the battery and fuel cell should meet the requirements of the vehicle's climbing performance (equation (16)). The peak power of the battery pack can be expressed as the product of its capacity and the maximum discharge rate equation (17):

$$
\begin{gathered}
P_{\text {stack_max }} \eta_{\text {con }} \geq \frac{P_{v}}{\bar{\eta}_{m} \eta_{\text {inv }}}, \\
P_{\text {stack_max }} \eta_{\text {con }}+P_{\text {bat_max }} \eta_{\text {bat }} \geq \frac{P_{c}}{\bar{\eta}_{m} \eta_{\text {inv }}}, \\
P_{\text {bat_ } \max }=Q_{\text {bat }} C_{\text {max }},
\end{gathered}
$$

where $P_{v}$ is the power demand for maximum velocity, $P_{c}$ is the power demand for climbing, $\bar{\eta}_{m}$ is the average efficiency of motor, $\eta_{\text {bat }}$ is the charge/discharge efficiency of battery, and $\eta_{i n v}$ and $\eta_{\text {con }}$ are the efficiency of DC-AC inverter and DC-DC converter, respectively.

\section{Results and Discussion}

This simulation is carried out with MATLAB; the interval is set to $10 \mathrm{~kW}$ and 25 for the fuel cell stack's peak power and the battery cells' number, respectively.

Under the current technical, lithium-ion batteries can maintain a discharge time of $5 \mathrm{~s}$ at the peak discharge rate of $30 \mathrm{C} \mathrm{[31].} \mathrm{However,} \mathrm{high} \mathrm{rate} \mathrm{discharge} \mathrm{will} \mathrm{seriously} \mathrm{affect}$ the life of the battery. In this paper, the maximum discharge rate of the battery is set as $20 \mathrm{C}$. In addition, the capacity of the battery cell used in the simulation is $3 \mathrm{Ah}$. Therefore, on the basis of equations (18) to (20), the minimum constraints of $P_{\text {stack } \max }$ and $n_{\text {bat }}$ will be estimated, as shown in Figure 11. 


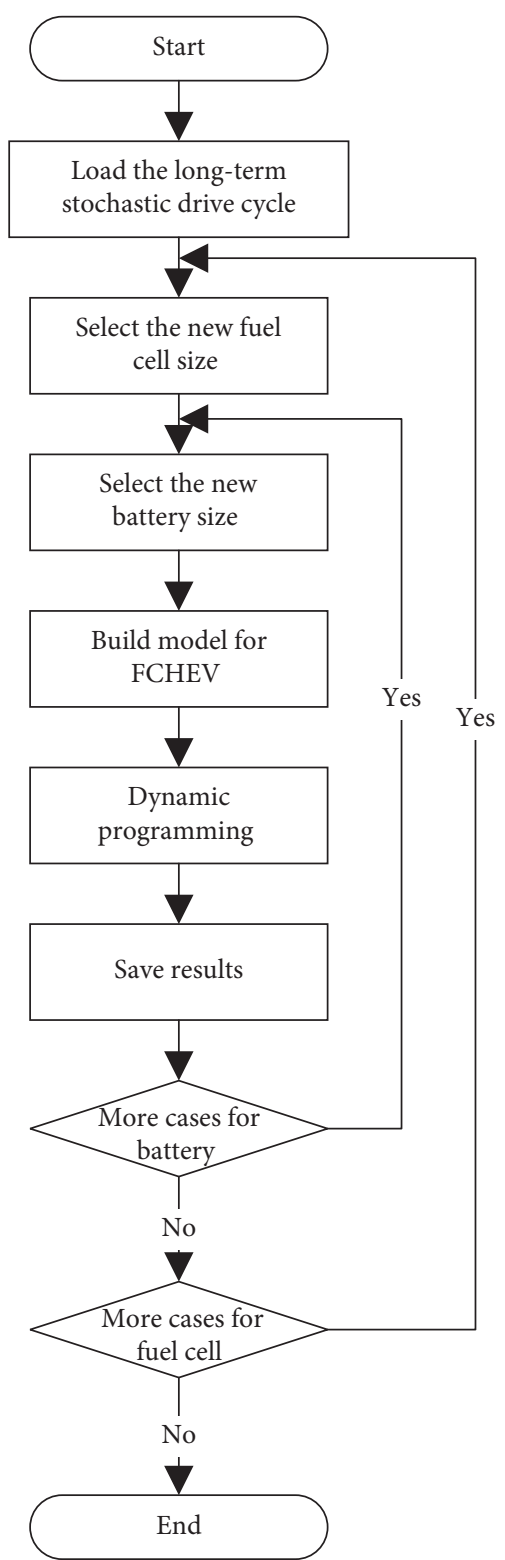

FIGURE 10: Flowchart of the sizing methodology.

Figure 12 shows the hydrogen consumption of vehicles with different sizes under long-term stochastic drive cycle. For a fair comparison, all the hydrogen costs are computed with the SOC deviation. Two conclusions can be obtained according to this figure:

(1) Starting from $P_{\text {stack_max }}=70 \mathrm{~kW}$, the hydrogen consumption decreases with the increasing of the peak power of fuel cell stack, but it increases when the peak power exceeds $120 \mathrm{~kW}$

(2) For a determined $P_{\text {stack_max }}$, the hydrogen consumption decreases with the increasing of the number of battery cells, but the slope of decline gradually decreases

To understand the causes of the changing of hydrogen consumption, we consider three relevant performance

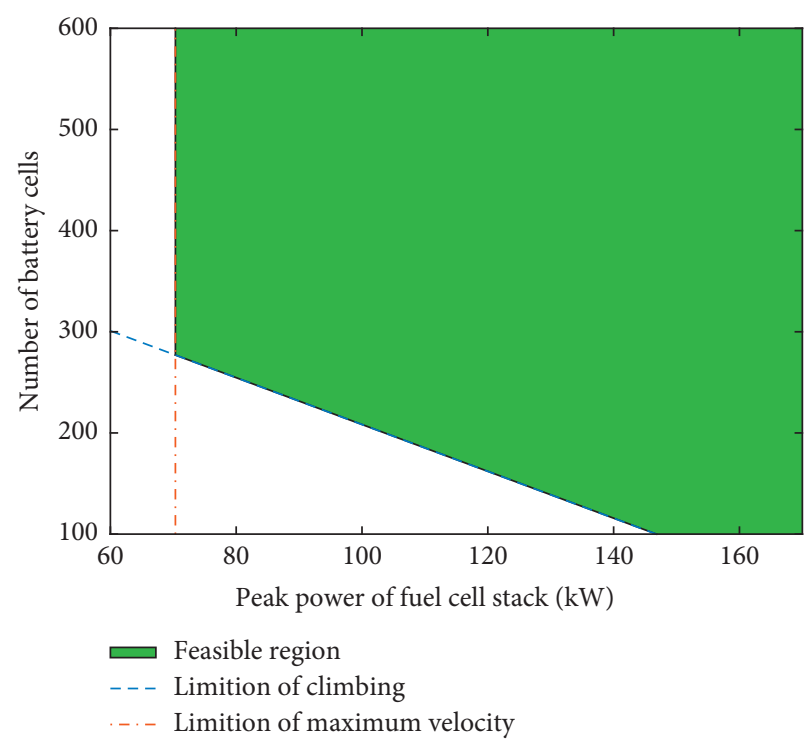

Figure 11: The minimum constraints of the $P_{\text {stack_max }}$ and $n_{\text {bat }}$.

indicators: the global propulsion efficiency, the brakingrecovery-energy to negative-load-power ratio, and the global fuel cell stack efficiency.

The global propulsion efficiency is formulated as follows:

$$
\eta_{g, \text { pro }}=\frac{\sum_{i=0}^{N} P_{\mathrm{veh}}^{+}(i) \Delta t}{L H V_{\mathrm{H}_{2}} \sum_{i=0}^{N} m_{H_{2}}(i) \Delta t} \times 100
$$

where $P_{\text {veh }}^{+}$is the positive vehicle power, $N$ is the length of stochastic drive cycle, $m_{H_{2}}$ is the hydrogen consumption, and $\Delta t$ is the simulation step.

The braking-recovery-energy to negative-load-power ratio is defined as follows:

$$
\gamma_{\mathrm{re}}=\frac{\sum_{i=0}^{N} P_{r e}(i) \Delta t}{\sum_{i=0}^{N} P_{v e h}^{-}(k) \Delta t} \times 100,
$$

where $P_{v e h}^{-}$is the negative vehicle power and $P_{r e}$ is the braking energy recovered by battery pack, which is formulated as follows:

$$
P_{r e}= \begin{cases}P_{b a t}, & \text { if } P_{\mathrm{veh}}<0 \\ 0, & \text { otherwise }\end{cases}
$$

The global fuel cell stack efficiency is defined as follows:

$$
\eta_{g, F C}=\frac{\sum_{i=0}^{N} P_{\text {stack }}(i) \Delta t}{L H V_{\mathrm{H}_{2}} \sum_{i=0}^{N} m_{\mathrm{H}_{2}}(i) \Delta t} \times 100 .
$$

To make the figure clearer, four types of fuel cell stack peak power are selected for this work: $P_{\text {stack_ } \max }=70 \mathrm{~kW}$, $P_{\text {stack_max }}=100 \mathrm{~kW}, P_{\text {stack_max }}=120 \mathrm{~kW}$, and $P_{\text {stack_max }}=$ $170 \mathrm{~kW}$. The rest results of other types are visible in Figure 13.

Figure 14 shows the effect of $P_{\text {stack_max }}$ and $n_{\text {bat }}$ on defined relevant performance indicators. Figure 14(a) shows the maximum global propulsion efficiency is approximately $55.56 \%$, which is reached when $P_{\text {stack_max }}=120 \mathrm{~kW}$ and $n_{\text {bat }}>1000$. Increasing or decreasing the type of fuel cell will 


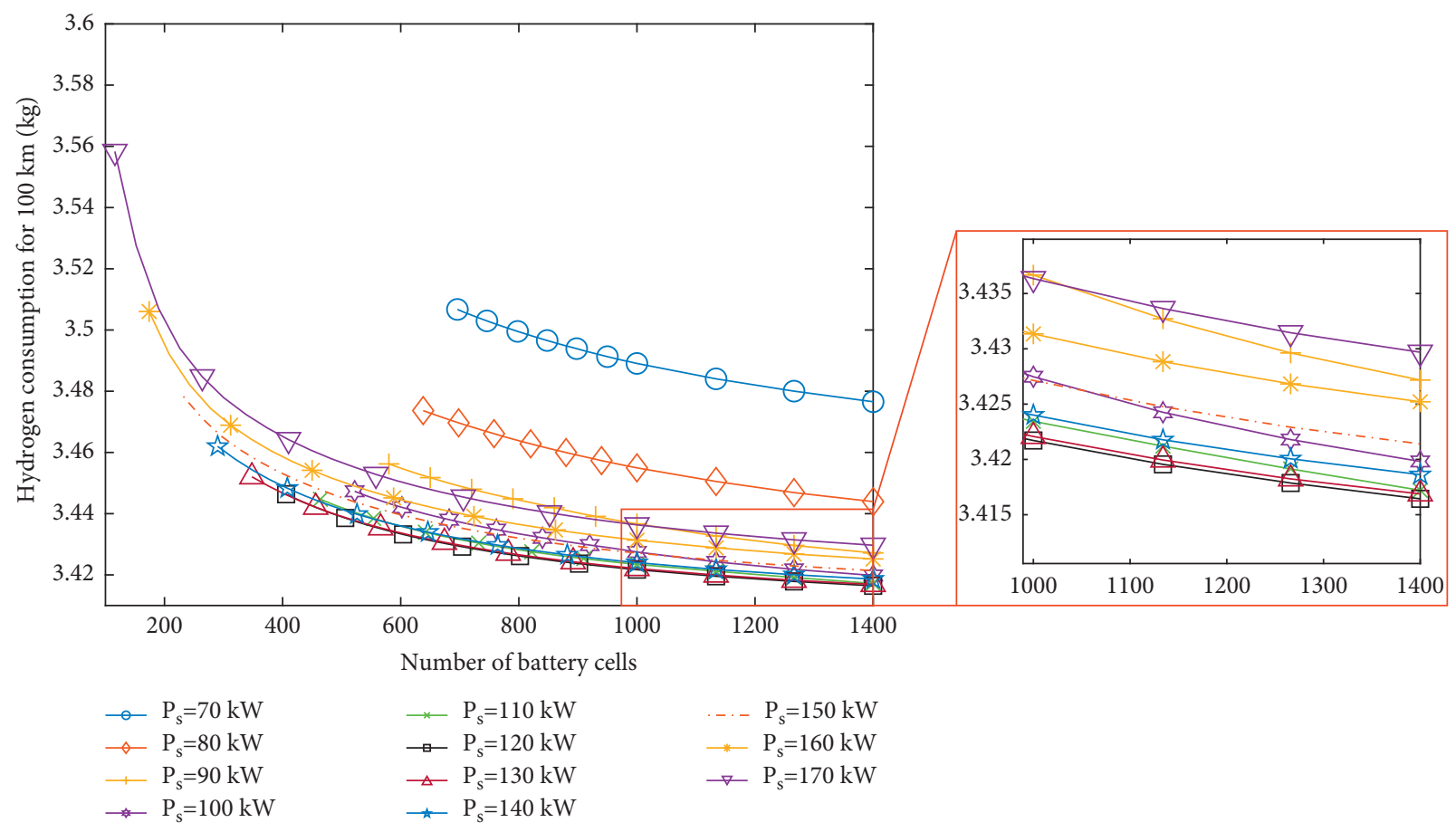

Figure 12: Hydrogen consumption in different sizes $\left(P_{s}: P_{\text {stack_max }}\right)$.
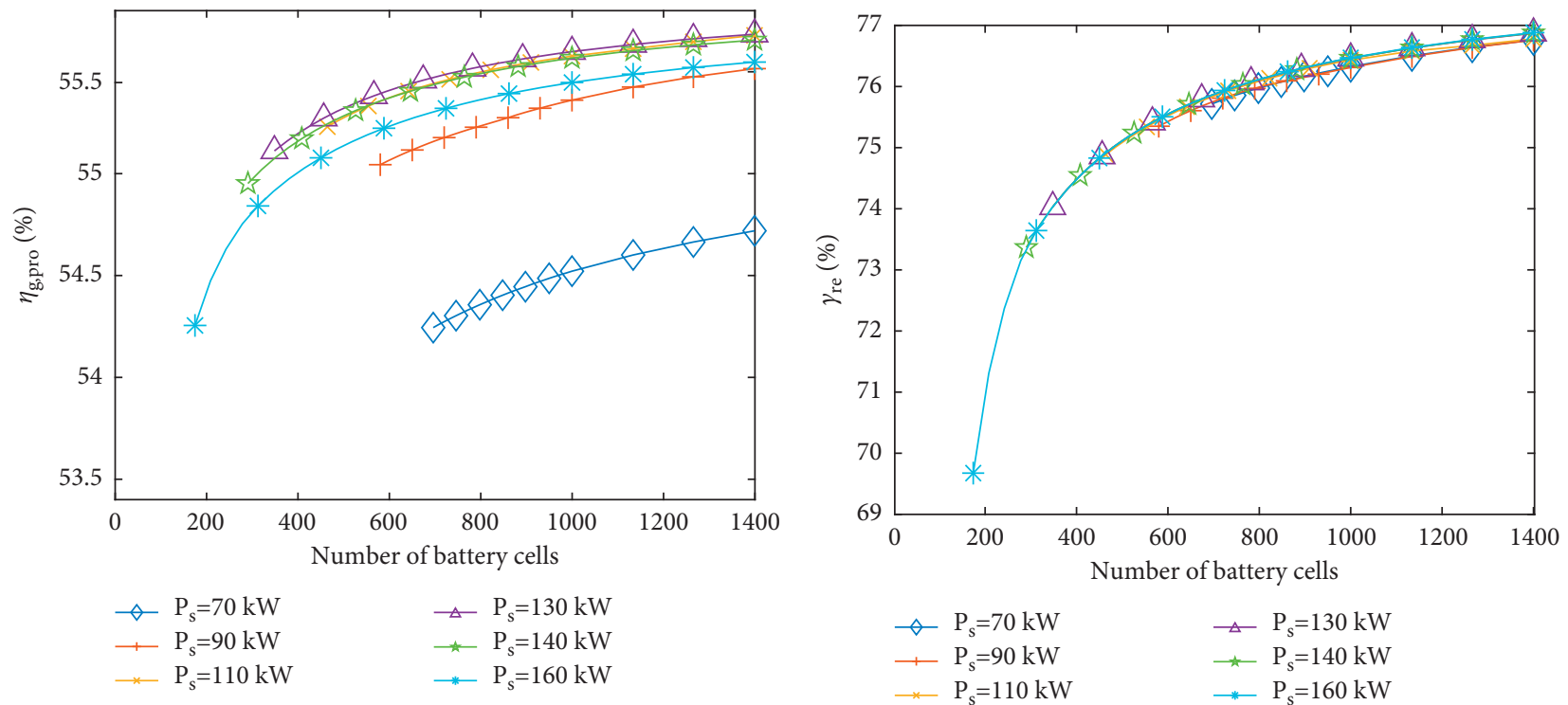

(a)

(b)

FIgURE 13: Continued. 


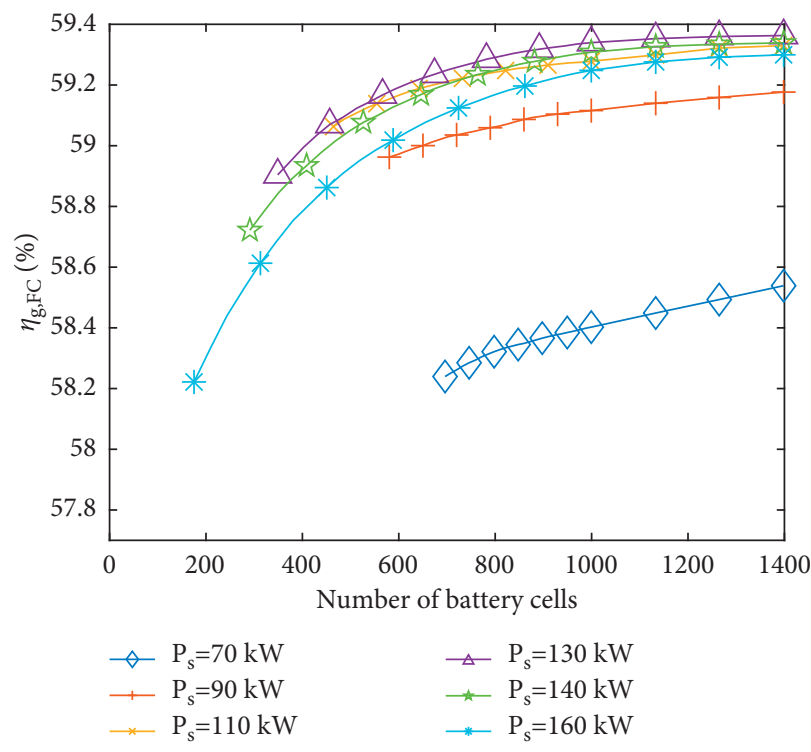

(c)

FIgURE 13: Comparative results of optimal costs.

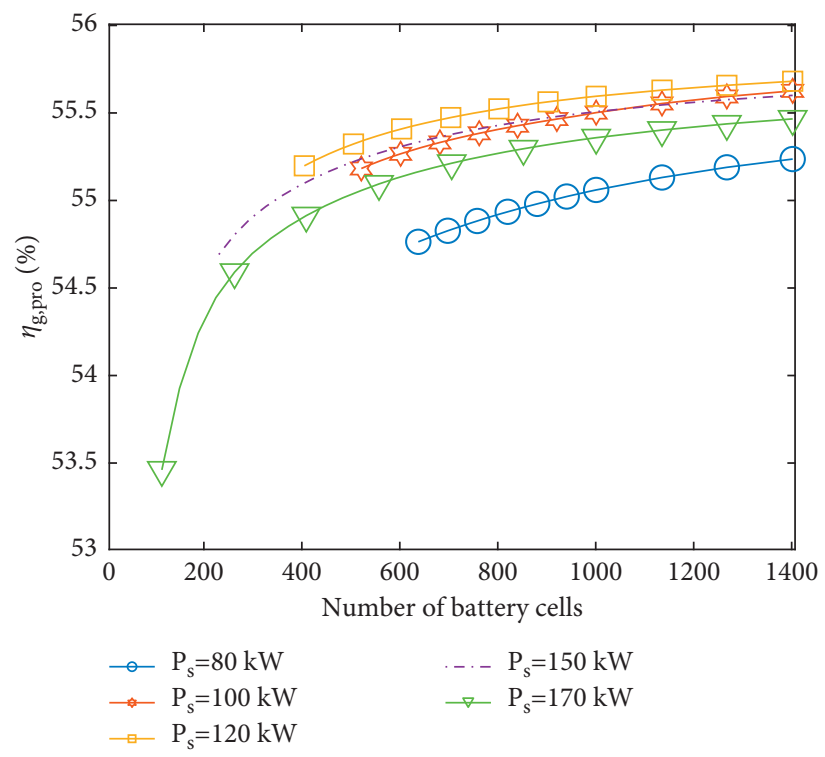

(a)

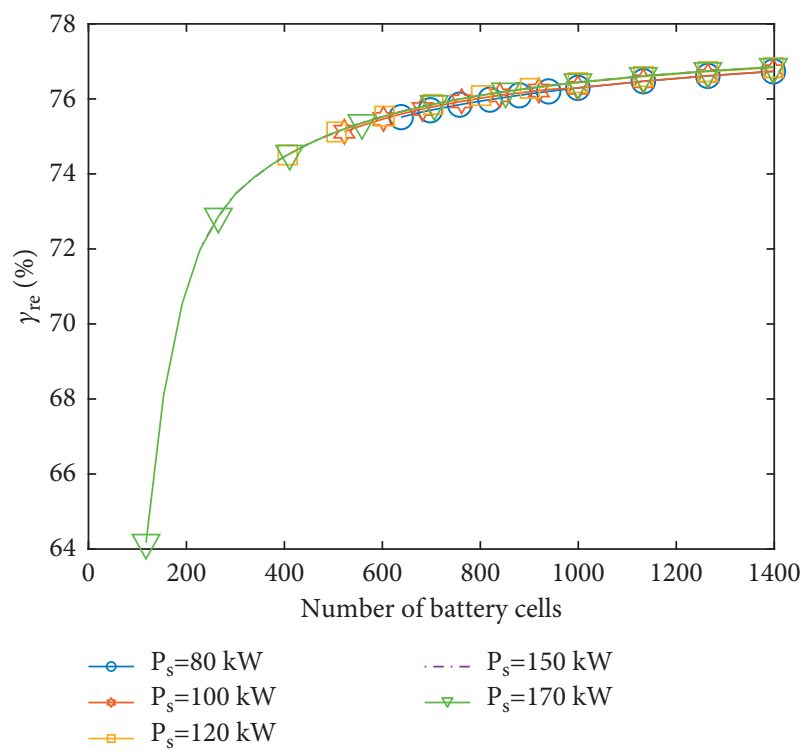

(b)

FIgURE 14: Continued. 


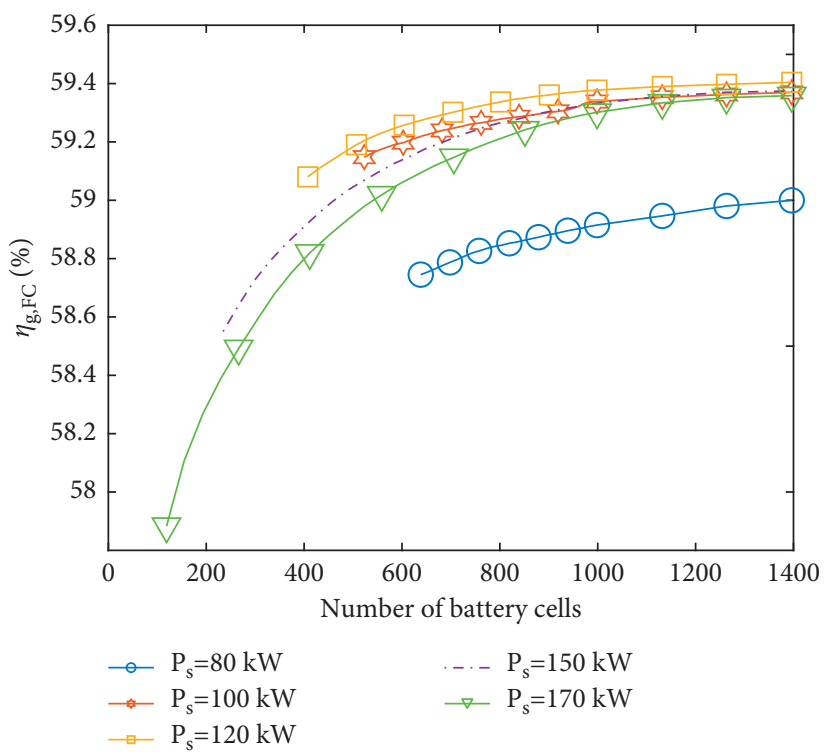

(c)

Figure 14: The test results of performance indicators with increasing cell number in different fuel cell sizes. (a) The global propulsion efficiency. (b) The braking-recovery-energy to negative-load-power ratio. (c) The global fuel cell stack efficiency.

worsen this indicator. On the other hand, increasing the number of battery cells can improve the global efficiency, but its growth trend gradually slows down and eventually to level. Figure 14(b) shows the size of fuel cell stack has less affected in braking-recovery-energy, while the number of battery cells has a great impact on this indicator: when $n_{\text {bat }}<400$, limited by the physical constraints (e.g., the maximum SOC or maximum voltage), the battery pack is not enough to recover all the braking energy. This means that friction brakes will dissipate power from fuel cell stack, which is not friendly to the global efficiency. Figure 14(c) shows that the global fuel cell stack efficiency performs best when $P_{\text {stack_max }}=120 \mathrm{~kW}$, and the increase in $n_{\text {bat }}$ will benefit this indicator. Similarly, the growth trend gradually slows down with the increase of $n_{\text {bat }}$.

The results in Figure 10 clarifies that the reduction of hydrogen can be achieved with an appropriate $P_{\text {stack_max }}$, and the increase of $n_{\text {bat }}$ will also benefits the fuel economy. It is beneficial to reduce the running cost, but the sharp increase in vehicle's price led by the increase of fuel cell and battery is unacceptable for both manufactures and users. Vehicle's price should also be considered as a further indicator.

To balance the cost of hydrogen consumption and component costs, a cost function which is defined as the cost per $100 \mathrm{~km}$ of the propulsion system is proposed, as shown in equation (18).

$$
J^{100}=J_{\text {stack }}^{100}+J_{\text {bat }}^{100}+J_{H_{2}}^{100} .
$$

In this function, the vehicle's cost $J^{100}$ is divided into fuel cell stack cost $J_{\text {stack }}^{100}$, battery cost $J_{\text {bat }}^{100}$, and hydrogen cost $J_{H_{2}}^{100}$. The fuel cell stack cost and the battery cost are cycle-normalized cost, as expressed in equations (19) and (20) [28, 29]. In addition, the cost of hydrogen is the value of hydrogen consumed when the vehicle's total driving distance reaches $100 \mathrm{~km}$ in the constructed long-term stochastic drive cycle, as shown in equation (21).

$$
\begin{aligned}
J_{\text {stack }}^{100} & =\frac{d}{s y_{v}}\left(1+P_{c} \frac{y_{v}+1}{2}\right) j_{\text {stack }} P_{\text {stack } \_ \text {max }}, \\
J_{\text {bat }}^{100} & =\frac{d}{s y_{v}}\left(1+P_{c} \frac{y_{v}+1}{2}\right) j_{\text {bat }} Q_{\text {bat }}, \\
J_{H_{2}}^{100} & =\frac{d}{X_{d c}} j_{H_{2}} m_{H_{2}},
\end{aligned}
$$

where $d$ is the length of cycle, $X_{d c}$ is the distance under a stochastic drive cycle, $s$ is the average travelled distance of the vehicle per year, $y_{v}$ is the vehicle lifetime, and $P_{c}$ is the yearly interest rate. Here, it is assumed that there are no components replaced during three-year operation, and the corresponding travelled distance is fifty thousand kilometres per year. These parameters above are given in Table $5 . j_{\text {stack }}$ is the fuel cell stack price per kilowatt, $j_{\text {bat }}$ is the battery price per kilowatt hour, and $j_{H_{2}}$ is the hydrogen price per gram. Three price conditions on the years 2020, 2025, and 2030 [32] are chosen for this study, as shown in Table 6.

Figure 15 shows the price impact on vehicle's total cost. Figure 14(a) shows the vehicle total cost with the price in 2020. In this case, the unit prices of fuel cells and battery cell are higher; the optimal cost is 25.07 US dollars per $100 \mathrm{~km}$ with the corresponding size to $P_{\text {stack } \max }=70 \mathrm{~kW}$ and $n_{\text {bat }}$ $=696$. The cost previews of 2025 and 2030 are shown in Figure 14(b) and 14(c) respectively. On the preview of 2025, benefiting from the production increases and technology improves, the unit price of fuel cell and battery will decrease rapidly, and the optimal cost will drop to 21.46 US dollars per $100 \mathrm{~km}$ with the corresponding size to $P_{\text {stack_max }}$ 
TABLE 5: The parameters of simulation.

\begin{tabular}{lcc}
\hline Description & Parameters & Value \\
\hline Length of cycle $(\mathrm{km})$ & $d$ & 100 \\
Yearly travelled distance $(\mathrm{km})$ & $s$ & $5 \mathrm{e} 4$ \\
Vehicle lifetime (years) & $y_{v}$ & 3 \\
Yearly interest rate $(\%)$ & $P_{c}$ & 5 \\
Stochastic cycle distance $(\mathrm{km})$ & $X_{d c}$ & 269 \\
\hline
\end{tabular}

TABLE 6: The price trends of components cost.

\begin{tabular}{lccc}
\hline Year & Fuel cell price $(\$ / \mathrm{kW})$ & Battery price $(\$ / \mathrm{kW})$ & Hydrogen price $(\$ / \mathrm{kg})$ \\
\hline 2020 & 70.41 & 256 & 5.32 \\
2025 & 37.00 & 173 & 5.05 \\
2030 & 29.84 & 117 & 5.03 \\
\hline
\end{tabular}

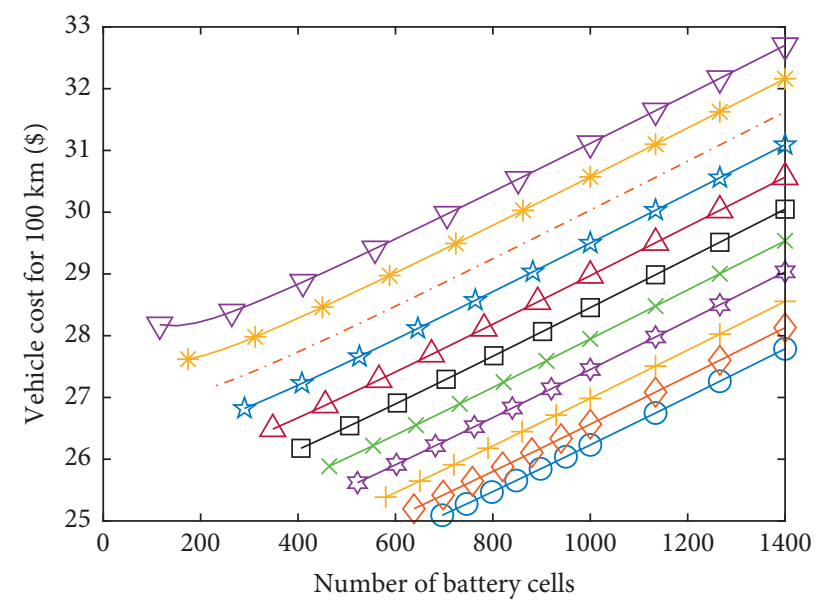

Number of battery cells

$$
\begin{aligned}
& \multimap \mathrm{P}_{\mathrm{s}}=70 \mathrm{~kW} \\
& \diamond \mathrm{P}_{\mathrm{s}}=80 \mathrm{~kW} \\
& \rightarrow \mathrm{P}_{\mathrm{s}}=90 \mathrm{~kW} \\
& \nleftarrow \mathrm{P}_{\mathrm{s}}=100 \mathrm{~kW}
\end{aligned}
$$

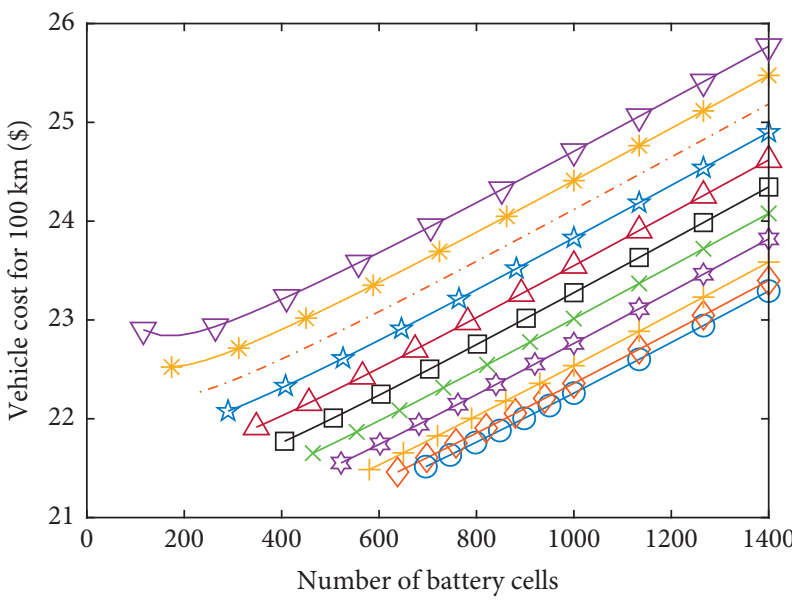

$$
\begin{aligned}
& \multimap \mathrm{P}_{\mathrm{s}}=70 \mathrm{~kW} \\
& \multimap \mathrm{P}_{\mathrm{s}}=80 \mathrm{~kW} \\
& \multimap \mathrm{P}_{\mathrm{s}}=90 \mathrm{~kW} \\
& \nleftarrow \mathrm{P}_{\mathrm{s}}=100 \mathrm{~kW}
\end{aligned}
$$$$
\begin{aligned}
& \star \mathrm{P}_{\mathrm{s}}=110 \mathrm{~kW} \\
& \nleftarrow \mathrm{P}_{\mathrm{s}}=120 \mathrm{~kW} \\
& \triangle \mathrm{P}_{\mathrm{s}}=130 \mathrm{~kW}
\end{aligned}
$$$$
\begin{aligned}
& \triangle \mathrm{P}_{\mathrm{s}}=130 \mathrm{~kW} \\
& \triangle \mathrm{P}_{\mathrm{s}}=140 \mathrm{~kW}
\end{aligned}
$$

... $\mathrm{P}_{\mathrm{s}}=150 \mathrm{~kW}$

$\rightarrow \mathrm{P}_{\mathrm{s}}=160 \mathrm{~kW}$

$\rightarrow \mathrm{P}_{\mathrm{s}}=170 \mathrm{~kW}$

(a)

Figure 15: Continued. 


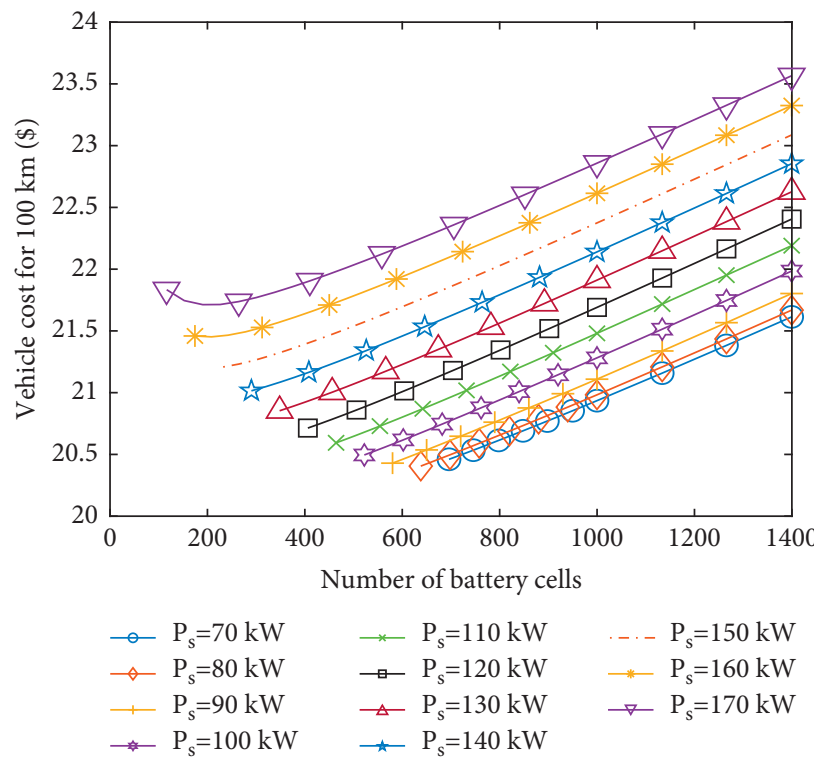

(c)

Figure 15: Performance indicators with increasing cell number in different fuel cell sizes. (a) The global propulsion efficiency. (b) The braking-recovery-energy to negative-load-power ratio. (c) The global fuel cell stack efficiency.

TABLE 7: The optimal sizes under different price conditions.

\begin{tabular}{lccc}
\hline & 2020 & 2025 & 2030 \\
\hline Optimal cost $(\$ / 100 \mathrm{~km})$ & 25.07 & 21.46 & 20.41 \\
Fuel cell size $(\mathrm{kW})$ & 70 & 80 & 80 \\
Cell number & 696 & 640 & 640 \\
String number & 4 & 4 & 4 \\
Bus nominal voltage & 626 & 576 & 576 \\
Cell number per string & 174 & 160 & 160 \\
\hline
\end{tabular}

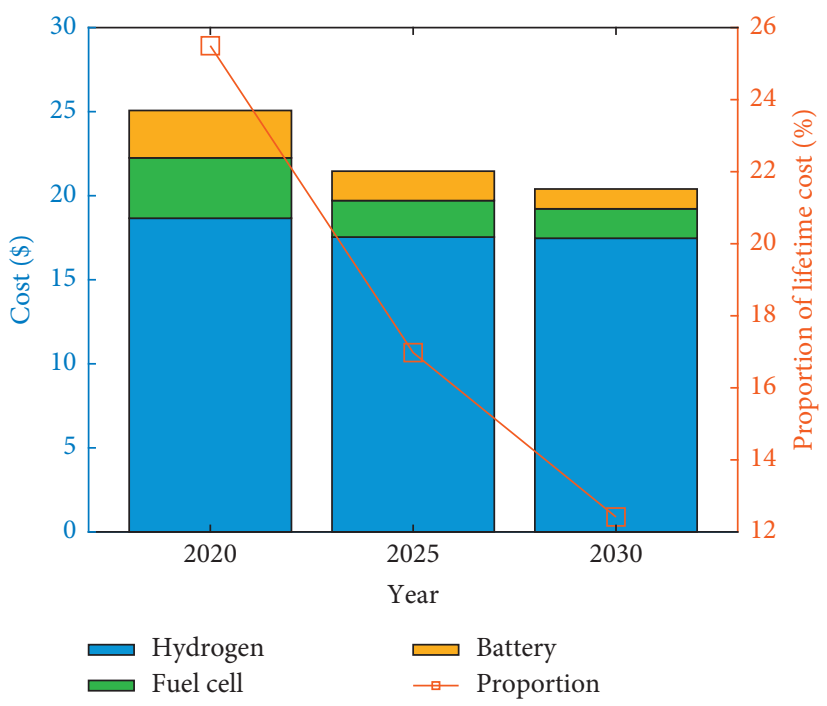

FIGURE 16: Vehicle costs for $100 \mathrm{~km}$ in different price conditions. (a) In 2020. (b) In 2025. (c) In 2030.

$=80 \mathrm{~kW}$ and $n_{\text {bat }}=640$. In 2030, with the further decrease of component prices, the optimal cost will drop to $20.41 \mathrm{US}$ dollars per $100 \mathrm{~km}$. The optimal sizes and costs for different price conditions are summarized in Table 7.
Figure 16 gives the comparative results of optimal costs under three price conditions. Based on the price trends in future, the optimal cost gradually decreases from 2020 to 2030. Compared to 2020, the decreases have reached $14.4 \%$ 
and $18.59 \%$ in 2025 and 2030, respectively. The main reason is the sharp decrease of fuel cell and battery price. At the same time, benefiting from the decrease of fuel cell and battery price, the proportion of lifetime cost decreases rapidly. For example, based on the price performance in 2020 , the proportion of lifetime cost is $25.56 \%$, and it decreases to $18.26 \%$ and $14.35 \%$ in 2025 and 2030 , respectively. Correspondingly, the hydrogen costs are $74.44 \%, 81.74 \%$, and $85.65 \%$ for the price performance in 2020,2025 , and 2030 , respectively. Along with the decreasing of hydrogen and components price, the hydrogen cost will be the more important performance index for vehicle cost in the near future.

\section{Conclusion}

This paper presents a sizing methodology for a heavy-duty fuel cell commercial vehicle on the basis of long-term stochastic drive cycle, parameters' scanning model, and DP-based EMS. The causes of hydrogen consumption under different sizes are studied in detail, and a discussion of the vehicle cost in the next decade is also given, on the basis of propulsion system and hydrogen price performance.

The main findings are as follows:

(1) The hydrogen consumption will be minimized when the peak power of fuel cell stack reaches $120 \mathrm{~kW}$, and the global propulsion efficiency will be improving with the battery cell number increase.

(2) When the number of battery cells is small, the global propulsion efficiency is affected by the braking-recovery-energy and the fuel cell stack efficiency, while as the number of battery cells continues to increase, the main cause for that is the fuel cell stack efficiency. Limited by the maximum efficiency of fuel cell stack, the effect of increasing the battery cells number on the global propulsion efficiency will gradually decrease.

(3) The size of $P_{\text {stack_max }}=70 \mathrm{~kW}$ and $n_{\text {bat }}=696$ will be a better choice for the vehicle total cost, under the consideration of the cost performance in 2020. The predictive analysis shows that the larger fuel cell stack will be suitable for the FCHEV with the decrease of fuel cell and battery price.

\section{Data Availability}

The datasets and codes of this paper for the simulation are available from the corresponding author upon request.

\section{Conflicts of Interest}

The authors declare that there are no conflicts of interest regarding the publication of this study.

\section{Authors' Contributions}

Weiguang Zheng carried out conceptualization, formal analysis, writing, review, and editing. Weiwei Xin was responsible for software and wrote the original draft. Enyong $\mathrm{Xu}$ carried out conceptualization and data curation. Shuilong He carried out conceptualization and formal analysis. Jirong Qin carried out supervision and project administration. Heng Wang carried out methodology and validation. All authors have read and agreed to the published version of the manuscript.

\section{Acknowledgments}

This study was supported by Innovation-Driven Development Special Fund Project of Guangxi (Guike AA18242033), Liuzhou Science Research and Planning Development Project (nos. 2020GAAA0403 and 2019AD10203), Liudong Science and Technology Project (20200108), and Innovation Project of GUET Graduate Education (2019YCXS008).

\section{References}

[1] L. Zhang, Y. Wang, and Z. Wang, "Robust lateral motion control for in-wheel-motor-drive electric vehicles with network induced delays," IEEE Transactions on Vehicular Technology, vol. 68, no. 11, pp. 10585-10593, 2019.

[2] X. Ding, Z. Wang, and L. Zhang, "Hybrid control-based acceleration slip regulation for four-wheel-independent-actuated electric vehicles," IEEE Transactions on Transportation Electrification, vol. 7, pp. 1976-1989, 2020.

[3] L. Guzzella and A. Sciarretta, Vehicle Propulsion Systems: Introduction to Modeling and Optimization, Springer, Heidelberg, Germany, 3 edition, 2013.

[4] X. Lv, Y. Qu, Y. Wang, C. Qin, and G. Liu, “A comprehensive review on hybrid power system for PEMFC-HEV: issues and strategies," Energy Conversion and Management, vol. 171, pp. 1273-1291, 2018.

[5] Y. Kim, M. Figueroa-Santos, N. Prakash, S. B. Stanley, J. Siegel, and M. Rizzo, "Co-optimization of speed trajectory and power management for a fuel-cell/battery electric vehicle," Applied Energy, vol. 260, Article ID 114254, 2020.

[6] F. Millo, J. Zhao, L. Rolando, C. Cubito, and R. Fuso, "Optimizing the design of a plug-in hybrid electric vehicle from the early phase: an advanced sizing methodology," ComputerAided Design and Applications, vol. 12, no. 1, pp. 22-32, 2015.

[7] S. Onori, L. Serrao, and G. Rizzni, Hybrid Electric Vehicles Energy Management Strategies, Springer, New York, USA, 1st edition, 2016.

[8] Y. Huang, H. Wang, A. Khajepour, H. He, and J. Ji, "Model predictive control power management strategies for HEVs: a review," Journal of Power Sources, vol. 341, pp. 91-106, 2017.

[9] Y. Hames, K. Kaya, E. Baltacioglu, and A. Turksoy, "Analysis of the control strategies for fuel saving in the hydrogen fuel cell vehicles," International Journal of Hydrogen Energy, vol. 43, no. 23, pp. 10810-10821, 2018.

[10] W. Zhou, L. Yang, Y. Cai, and T. Ying, "Dynamic programming for new energy vehicles based on their work modes Part II: fuel cell electric vehicles," Journal of Power Sources, vol. 407, pp. 92-104, 2018.

[11] X. Li, Y. Wang, D. Yang, and Z. Chen, "Adaptive energy management strategy for fuel cell/battery hybrid vehicles using Pontryagin's Minimal Principle," Journal of Power Sources, vol. 440, Article ID 227105, 2019.

[12] X. Lv, Y. Wu, J. Lian et al., "Energy management of hybrid electric vehicles: a review of energy optimization of fuel cell hybrid power system based on genetic algorithm," Energy 
Conversion and Management, vol. 205, Article ID 112474, 2020.

[13] G. Paganelli, S. Delpra, T. M. Guerra, J. Rimaux, and J. J. Santin, "Equivalent consumption minimization strategy for parallel hybrid Powertrains," in Proceedings of the Vehicular Technology Conference, pp. 2076-2081, Birmingham, AL, USA, May 2002.

[14] H. Borhan, A. Vahidi, A. M. Phillips, M. L. Kuang, I. V. Kolmanovsky, and S. Di Cairano, "MPC-based energy management of a power-split hybrid electric vehicle," IEEE Transactions on Control Systems Technology, vol. 20, no. 3, pp. 593-603, 2012.

[15] Z. Chen, N. Guo, E. Xiao, J. Shen, and P. Dong, "A hierarchical energy management strategy for power-split plug-in hybrid electric vehicles considering velocity prediction," IEEE Access, vol. 6, Article ID 33261, 2017.

[16] N. Guo, X. Zhang, Y. Zou, L. Guo, and G. Du, "Real-time predictive energy management of plug-in hybrid electric vehicles for coordination of fuel economy and battery degradation," Energy, vol. 214, Article ID 119070, 2021.

[17] Z. Hu, J. Li, L. Song et al., "Multi-objective energy management optimization and parameter sizing for proton exchange membrane hybrid fuel cell vehicles," Energy Conversion and Management, vol. 129, pp. 108-121, 2016.

[18] S. M. Lukic and A. Emadi, "Effects of drivetrain hybridization on fuel economy and dynamic performance of parallel hybrid electric vehicles," IEEE Transactions on Vehicular Technology, vol. 53, no. 2, pp. 385-389, 2004.

[19] M.-J. Kim and H. Peng, "Power management and design optimization of fuel cell/battery hybrid vehicles," Journal of Power Sources, vol. 165, no. 2, pp. 819-832, 2007.

[20] D. Feroldi and M. Carignano, "Sizing for fuel cell/supercapacitor hybrid vehicles based on stochastic driving cycles," Applied Energy, vol. 183, pp. 645-658, 2016.

[21] S. H. Karaki, R. Dinnawi, R. Jabr, R. Chedid, and F. Panik, "Fuel cell hybrid electric vehicle sizing using ordinal optimization," SAE International Journal of Passenger Cars-Electronic and Electrical Systems, vol. 8, no. 1, pp. 60-69, 2015.

[22] X. Hu, N. Murgovski, L. Johannesson, and B. Egardt, "Energy efficiency analysis of a series plug-in hybrid electric bus with different energy management strategies and battery sizes," Applied Energy, vol. 111, pp. 1001-1009, 2013.

[23] X. Hu, L. M. Johannesson, and B. Egardt, "Optimal dimensioning and power management of a fuel cell/battery hybrid bus via convex programming," IEEE/ASME transactions on mechatronics, vol. 20, pp. 457-468, 2014.

[24] X. Hu, N. Murgovski, L. M. Johannesson, and B. Egardt, "Comparison of three electrochemical energy buffers applied to a hybrid bus powertrain with simultaneous optimal sizing and energy management," IEEE Transactions on Intelligent Transportation Systems, vol. 15, no. 3, pp. 1193-1205, 2014.

[25] X. Hu, S. J. Moura, N. Murgovski, B. Egardt, and D. Cao, "Integrated optimization of battery sizing, charging, and power management in plug-in hybrid electric vehicles," IEEE Transactions on Control Systems Technology, vol. 24, pp. 1036-1043, 2015.

[26] M. H. Karaoğlan, N. S. Kuralay, and Z. Colpan, "The effect of gear ratios on the exhaust emissions and fuel consumption of a parallel hybrid vehicle powertrain," Journal of Cleaner Production, vol. 210, pp. 1033-1041, 2018.

[27] T. Markel, A. Brooker, T. Hendricks et al., "ADVISOR: a systems analysis tool for advanced vehicle modeling," Journal of Power Sources, vol. 110, no. 2, pp. 255-266, 2002.
[28] A. Sciarretta and L. Guzzella, "Control of hybrid electric vehicle," IEEE Control Systems Magazine, vol. 27, pp. 60-70, 2007.

[29] O. Sundstrom and L. Guzzella, "A generic dynamic programming Matlab function," in Proceedings of the 18TH IEEE International Conference Conference on Control Appllcations, Saint Petersburg UK Russia, July 2009.

[30] O. Sundström, D. Ambühl, and L. Guzzella, "On implementation of dynamic programming for optimal control problems with final state constraints," Oil \& Gas Science and Technology - Revue de l'Institut Français du Pétrole, vol. 65, no. 1, pp. 91-102, 2010.

[31] E. T. Yidiz, Q. Faroqi, S. Anwar, Y. Chen, and A. Izadian, "Nonlinear constrained component optimization of a plug-in hybrid electric vehicle powertrain," in Proceedings of the 25th World Battery, Hybrid and Fuel Cell Electric Vehicle Symposium \& Exhibition, Shenzhen, China, September 2010.

[32] H. Li, Y. Zhou, H. Gualous, H. Chaoui, and L. Boulon, "Optimal cost minimization strategy for fuel cell hybrid electric vehicles based on decision-making framework," IEEE Transactions on Industrial Informatics, vol. 17, no. 4, pp. 2388-2399, 2021. 